\title{
SECTORAL LINGUOCOUNTRY STUDIES \\ (on the example of medical linguo-Ukrainian studies)
}

\author{
Anna Onkovych \\ Doctor of Pedagogical Sciences, Professor \\ Kyiv Medical University \\ (Kyiv, Ukraine) \\ email: onkan@ukr.net
}

\begin{abstract}
The problems of linguocountry study have been intensively studied in Ukraine - in the methods of teaching Russian and then Ukrainian to foreign citizens. The achievements of Ukrainian researchers and practitioners have aroused considerable interest among scholars of linguodidactic processes. The term linguo-Ukrainian studies were to some extent a borrowing, a travesty, but by introducing it, Ukrainian linguodidacticians successfully developed this direction in the methodology of teaching Ukrainian as a foreign language and sought to expand the search of researchers in this promising and relevant direction. Certain successes have been achieved. Since then, both linguo-country study and linguo-Ukrainian issues have been developed in parallel in Ukraine.

In recent years, the Ukrainian language of professional communication has been compulsory for higher education institutions. The Ukrainian language for non-philologists has attracted the attention of many professionals. Study guides, methodological developments and new teaching technologies have appeared. The need to develop a country study direction in this course has arisen, which is demonstrated in this article using the example of teaching the Ukrainian language at a medical institute.

The author has developed a special course "Medical linguo- Ukrainian studies", the purpose of which is to enable students to assimilate not only terminological, but also Ukrainian- studies material systematically. Such course will contribute to national education of students by means of language, culture and Ukrainian studies, will guarantee high intellectual development of future specialists, as well as improvement of their professional, linguistic, culturological, media, socio-cultural and communicative competences.
\end{abstract}

Key words: language and culture, linguo-cultural studies, linguo-Ukrainian studies, terminological system, medical terminology, branch (profile) linguo-cultural studies, branch (profile) linguo-Ukrainian studies, medical (pharmaceutical) linguo-Ukrainian studies.

\section{ОТРАСЛЕВОЕ ЛИНГВОСТРАНОВЕДЕНИЕ}

\section{(на примере медицинского лингвоукраиноведения)}

\author{
А. В. Онкович \\ доктор педагогических наук \\ профессор кафедры украинского и латинского языков \\ Киевский медицинский университет
}

(Киев, Украина)

email: onkan@ukr.net 


\section{Памяти научного руководителя академика Виталия Григорьевича Костомарова}

Аннотация. Лингвострановедческая проблематика интенсивно и заинтересованно разрабатывалась в Украине - в методике преподавания русского. а потом и украинского языка иностранным гражданам. Достижения украинских исследователей и практиков вызывали значительный интерес у исследователей лингводидактических процессов. Термин лингвоукраиноведение был в определенной степени заимствованием, калькой, однако, внедряя его, украинские лингводидакты успешно разрабатывали это направление в методике преподавания украинского языка как иностранного и стремились расширить поиск исследователей в этом перспективном и актуальном направлении. Определенные успехи были достигнуты. С тех пор в Украине параллельно разрабатывались и лингвострановедческая, и лингвоукраиноведеческая проблематики.

Ключевые слова: язык и культура, лингвострановедение, лингвоукраиноведение, терминосистема, медицинская терминология, отраслевое (профильное) лингвострановедение, отраслевое (профильное) лингвоукраиноведение, медицинское (фармацевтическое) лингвоукраиноведение.

ВВЕДЕНИЕ. В последние годы украинский язык профессионального общения обязателен для изучения в высших учебных заведениях. Украинский язык для нефилологов привлек внимание многих профессионалов. Появились учебные пособия, методические разработки, новые технологии преподавания. Возникла необходимость разработки в этом курсе и страноведческой направленности, что и продемонстрировано в данной статье на примере преподавании украинского языка в медицинском вузе.

Автором разработан специальный курс «Медицинское лингвоукраиноведение», задача которого состоит в том, чтобы дать студентам возможность системно усвоить не только терминологический, но и украиноведческий материал. Такой курс будет способствовать национальному воспитанию студентов средствами языка, культуры и украиноведения, обеспечит высокое интеллектуальное развитие будущих специалистов, а также повышение их профессиональной, языковой, культурологической, медиаобразовательной, социокультурной и коммуникативной компетенций.

АКТУАЛЬНОСТЬ ИССЛЕДОВАНИЯ. Когда несколько лет назад мы впервые ввели в учебно-методическое обращение термин лингвоукраиноведение (лінгвокраїнознавство) (Oncovich 1993; 1999; 2003), то, прежде всего, хотели привлечь внимание украинских лингводидактов к тем новым поискам, которые велись в мире и находили отражение в ряде публикаций - по культурной грамотности в США, по культуре и цивилизации во Франции, по лингвострановедению на территории бывшего СССР (Vereshagin, Kostomarov 1999; Vereshagin, Kostomarov 1973; Донець 2002). Лингвоукраиноведение ныне - отрасль, которая исследует язык как составляющую часть украинской культуры, анализирует явления культуры через украинский язык.

Вдохновлял пример международной конференции «Язык и культура», которая ежегодно проходит в Киеве в конце июня. (Отметим, что в этом году это будет в тридцатый раз). Программа конференции предусматривает пленарные заседания, работу секций, круглые столы, широкую культурную программу. Работа секций традиционно проходит по направлениям, которые воспроизводят «развитие» понятия «Язык и культура»: Философия языка и культуры. Психология языка и культуры. Национальные языки и культуры в их специфике и взаимодействии. Лингвокультурологическая интерпретация текста. Межкультурная коммуникация. Язык современного искусства. Язык и средства массовой 
коммуникации. Художественная литература в контексте культуры. Теория и практика перевода. Культурологический подход к преподаванию языка и литературы. Киевская конференция заслуживает отдельного анализа и по форме проведения, и по содержанию докладов. Ныне она имеет свой сайт, в открытом доступе - публикации материалов конференции. А начиналось все с выпуска тезисов к первой конференции (Onkovic A.D. \& Onkovic G.V. 2018). Сейчас доклады публикуются в периодическом научном издании по филологическим дисциплинам (языкознание, литературоведение) «ЯЗЫК И КУЛЬТУРА». Вышло уже более 200 томов. Традиции, заложенные в дни проведения первых конференций, продолжаются по сей день.

Сегодня же мы говорим о необходимости актуализации в этом русле «национального» понятия, соприкасающегося с отраслевой терминосистемой. Отраслевое лингвострановедение (в нашем случае - лингвоукраиноведение) можно представить в виде пирамидЫ: ЯЗЫК - КУЛЬТУРА - ПРОФЕССИОНАЛЬНАЯ ТЕРМИНОЛОГИЯ. ВерхУшка пирамиды, как и ее фундамент, меняется в зависимости от цели занятия. Этого частично касаются специалисты, обращающиеся к истории профессионального общенния в курсе «Українська мова за професійним спрямуванням» (Shevchuk 2011). Исследователи отмечают, что профессиональная научная терминология «не является постоянной системой, она живет, меняется, приспосабливается к потребностям современности. История развития данной науки, изменение научных взглядов, интеграция и дифференциаций научных дисциплин, культурные связи, влияние лексико-семантической системы языка - все это отражается на состоянии как терминологической системы, так и отдельных терминов» (Ganitkevich Yaroslav).

С целью привлечь внимание к «треугольнику», где «на верху» - профессиональная терминология, а фундаментом являются язык и культура, и таким образом активизировать образовательные поиски в актуализации профессиональных знаний студентов, мы в данной статье в качестве примера лбращаемся к исследованиям по медицинской терминологии. Украинские исследователи, работающие в этом направлении, историки медицины зотмечают, что медицинская лексика является одной из древнейших профессиональных терминосистем. Она формировалась на собственной языковой основе, усваивая все то, что уже было выработано мировой цивилизацией (Ganitkevich 2002; Misnik 2002; Pavlovskiy 2005; Petrova1998; Petruh 2014).

Из истории. Лингвострановедческая проблематика интенсивно и заинтересованно разрабатывалась в Украине - в методике преподавания русского. а потом и украинского языка иностранным гражданам. Достижения украинских исследователей и практиков вызывали значительный интерес у исследователей лингводидактических процессов. Термин лингвоукраиноведение был в определенной степени заимствованием, калькой, однако, внедряя его, мы хотели направить поиск украинских лингводидактов в этом перспективном и, как нам казалось, актуальном направлении. Со временем пришло понимание, что речь идет, собственно, о двух методических явлениях лингводидактики - лингвоукраиноведении и украинолингвоведении (Oncovich 1997; 2001; 1999).

Потребность в обоих терминах, по нашему мнению, определялась развитием методической науки. Практика показала, что эти ответвления могут быть отдельными дидактическими направлениям. 
На первый взгляд может показаться полное тождественность этих понятий (Oncovich 2003; 1999).

Однако они, несмотря на общие терминосоставляющие, отличаются. Мы считали, что термин лингвоукраиноведение должен обслуживать. в первую очередь, дидактические потребности украинского языка. Он включает ряд понятий, языковых явлений, факты из истории языка, происхождения слов, интересных явлений вокруг слова - все, что имеет отношение к украинскому языку как к мировому феномену. Но в лексическом запасе языков мира немало таких слов, которые становятся языковыми знаками определенной национальной культуры: в одном языке - образы, отражающие наличие ив, прудов, тополей, реки или моря: в другой - эвкалиптов, верблюдов, оазисов или пустынь: в третьей господствуют образы бесконечно высокого неба, бескрайней степи, таинственновозвышенных гор, а в четвертой - сжатость джунглями или ущельями, безмолвие ледников или тундры (Кononenko 1996, 121), ведь речь о природе и является не только формой бытия каждого этноса (народа, нации), но и самим бытием.

На языке зафиксировано явления различных культурных стратов, разных миров. Однако каждый язык содержит явления национальной культуры, сконденсированные в слове. Они по-разному воспринимаются в том или ином возрасте, носителем той или иной культуры. В любом случае за этим словом стоит определенный текст - вербальный или невербальный, знания по тому или иному виду человеческой деятельности. И это - область украинолингвоведения. Поэтому, на наш взгляд, возникла необходимость еще в одном лингвокультурологическом термине - «слово-тема», которому принадлежит видное место в расширении культурной памяти учащихся. Мы проиллюстрировали это в пособии «Хата: слово-тема и культурознак» (Onkovich 2001; 1994; 2010).

Мы привели только один пример того, как идеи, изложенные Е. Верещагиным и В. Костомаровым в начале 70-х годов в книге «Язык и культура» (Vereshagin, Kostomarov 1973), приобретали развития, распространения. Впоследствии, по мнению авторов, суть идей этой работы не устарела, однако форма требовала модификации (Vereshagin, Kostomarov 1999; Donets 2002).

Активизировалось понятие «лингвокультурология» с термином «лингвокультурема» (Vorobyev 1997). Упрощая и схематизируя ситуацию, исследователи различали: а) слово (выражение, фразу, фразеологизм) - единицу, значение которой является обобщение примеров ее применения; б) термин - единицу, значение которой задано более или менее произвольной дефиницией; в) лингвокультурему - единицу, значение которой является репрезентация какого-то значимого текста (Vorobyev 1997, 76).

Со временем В.Г.Костомаров и Н.Д.Бурвикова $(1999,252-260)$ пришли к выводу считать целесообразным каждой из единиц семиотической системы языка, за которой стоит определенный когнитивный смысл, определенное знание, определенная информация (иногда даже оформлена в текст), дать общее имя, назвав их логоеэистемами (с греческого: логос слово, эпистема - знание), то есть знание, которое хранится в единице языка. Логоеэпистемы функционируют в текстах как голос прошлого и часто используются при объяснении современных проблем. Источником логоэпистемы может быть: 1) народное поэтическое творчество; 2) памятники истории и общественной мысли, а также специальные исследования по различным отраслям знания; 3) высказывания выдающихся деятелей науки, искусства и литературы, 4) литературные произведения как вторичные смоделированные 
системы; 5) выдающиеся личности как модель национальной личности; 6) мысли и суждения иностранцев о нации и культуре как сопоставимый фон. В это время мы и выделили новые лингводидактичческие понятия слово-тема и культурознак, развивая мысли исследователей лингвистов, культурологов. Они отличаются от «просто слова» тем, что, как результат компрессии определенных знаний, требуют приемов по развертыванию этих знаний в методическом поле - прежде культурологического, профессионально ценностного плана. Понятие «слово-тема» - единица, значение которой предполагает презентацию какого-то значимого знания, а «культурознак» - единица, которая это значимое знание вобрала в себя (Oncovich 1994; 2010; 2011).

ОСНОВНАЯ ЧАСТЬ. Мы считаем, что тема отраслевого лингвострановедения должна развиваться. В разработанном нами спецкурсе «Отраслевое лингвоукраиноведение» для студентов медицинского профиля впервые делается попытка включить в образовательное пространство это новое профессионально ориентированное явление - отраслевое лингвоукраиноведение (на примере приобретения медицинской / фармацевтической специальности). Цель изучения курса - научить студентов владеть профессиональными украиноведческими знаниями, развивать их речь и мышление с опорой на эти знания, развивать и обогащать образно-эмоциональную память, активизировать понятие «отраслевое \ медицинское лингвоукраиноведение». В программе учитываются межпредметные связи новой дисциплины с курсами социально-гуманитарных и профильных дисциплин. Курс условно делится на два блока: 1) общее лигвоукраиноведение и 2) отраслевое лингвоукраиноаедение.

Исследователи считают, что медицинскую терминологию следует развивать и нормализовать с учетом ее национальных и международных функций и специфических черт - наличием подавляющего числа терминов иноязычного происхождения. Н.Мисник и Л.Симоненко отмечают, что в решении проблемы взаимодействия национальных и международных компонентов выделяют такие три аспекта: 1- учет традиций терминоупотребления, которые в медицине складывались на протяжении веков; 2 - целесообразность использования имеющихся в родном языке эквивалентных иностранных терминов; 3 - создание новых терминов по словообразовательным моделям украинского языка (Місник 2002).

Среди собственно лингвистических проблем, связанных с развитием украинских терминов, содержащих специфические национально языковые черты, сегодня Я. Ганиткевич выделяет шесть: 1) разработка критериев антирусификации современных терминосистем, в связи с чем требует проработки проблема россиянизмов в украинской терминологии ; 2) выявление англицизмов (американизмов) в разных терминосистемах и научное обоснование целесообразности их употребления; 3) выяснение роли и места интернационализмов и их национальных соответствий в разных терминосистемах; 4) способы отбора названий опредметненных действий; 5) способы отбора наименований опредметненных признаков; 6) орфоэпические и орфографические проблемы. Названные вопросы означают только первое приближение к комплексу проблем, связанных с национальным своеобразием современного украинского термина. Я.Ганиткевич считает исследование путей формирования украинской медицинской терминологии, которая является основой украинского научного медицинского языка и литературы, важной проблему украинской истории медицины, а затем - должен занимать почетное место в нашем «треугольнике» в «углу» КУЛЬТУРА.

Медицинскую лексику исследователи справедливо считают одной из древнейших профессиональных терминологий и отмечают, что она формировалась на собственной 
языковой основе, усваивая все то, что в момент его создания выработала мировая цивилизация. Основные украинские медицинские названия-термины возникли еще в праславянскую эпоху, отражая жизнь и потребности человека. Первые слова-термины для обозначения частей тела, недугов и их лечение появились в устном народном праукраинском языке, в преданиях, легендах, устном народном творчестве и в народном лекарстве того времени. Некоторые названия болезней, пожалуй, сохранились еще с дохристианских времен (Ganitkevich 2002; Petruh 2014). Народные анатомические, физиологические и патологические названия-термины появились в процессе развития народной и традиционной медицины, закрепились в народно-разговорной речи, среди прочего эмпирическим опытом стали передаваться от поколения к поколению.

Высокий уровень культуры и знаний был в Киевской Руси-Украине. Народные лекари, которые действовали в X-XII вв., развивали и уточняли народные медицинские названия. Однако письменных памятников того времени, связанных с народной медициной, почти нет.

Историю развития медицинской терминологии украинские исследователи прослеживают через появление медицинских словарей. Первые словари медицинской терминологии начали появляться еще в XVI-XVII веках. Не будем развивать эту тему, отметим только, что она может быть отдельным разделом при введении нового курса по профессиональному (отраслевому) лингвоукрановедению.

В 70-х гг. XIX в., почти одновременно на Приднепровской Украине и в Галичине, появляются украинские научно-популярные издания на медицинские темы, первые научные медицинские публикации на украинском языке, возникла необходимость в современной научной медицинской терминологии. Научная обработка украинской терминологии происходила наиболее активно в начале XX века. Одновременно с использованием слов медицинских терминов украинского устного народного языка и литературного языка началось становление украинской медицинской профессиональной терминологии, составление первых профессиональных медицинских словарей. На страницах основанного Е.Озаркевичем «Врачебного сборника НТШ» (1898) впервые в украинской истории начади систематически публиковать научные медицинские труды на украинском языке, в конце каждого выпуска подавался немецко- и латино-украинский словарик терминов. Е.Озаркевич отмечал, что при образовании украинских терминов нужно учитывать опыт других народов, в частности немцев, чехов, поляков, а также использовать народный язык. В его словаре преобладала тенденция замены латинских и немецких терминов оригинальными названиями, случались некоторые заново созданные слова-термины. В то же время, в словаре нет таких простонародных выражений, например баба-пупоризка, которые представлены в некоторых современных медицинских словарях и стали предметом злобной критики недоброжелателей. Исследователи отмечают, что с позиций сегодняшнего дня можно многое критиковать в словаре Е.Озаркевича, но он приводит 39 терминов для обозначения различных абсцессов, 24 термина различных шелестов (шумов), в частности «спіжсовий, кляскаючий, тріскання, скриплення, віддиховий, булькотячий, пильниковий, спадаючого дощу, дмухаючий, муркотання» и т.п.

Немало терминов из словаря Е.Озаркевича выдержали испытание временем и используются до сих пор: безвладність, протиотрути, яєчник, місячка, недокровність, знечулення, збочення, корч, протизапальний, вилив крови, кровоток, кровоносні судини, обіг крові, корткозорість и др. 
В Восточной Украине работа над научной медицинской терминологией началась в медицинской секции Украинского научного общества (УНО) в Киеве, которую возглавлял М.Галин. Вопрос украинской медицинской терминологии возник одновременно с первыми публикациями на украинском языке научно-медицинских работ в изданиях УНО. Украинские врачи-ученые - члены секции, впервые на Приднепровье стали одновременно пионерами - создателями современной украинской научной медицинской терминологии. М.Галин большое внимание уделял вопросам терминологии, подготовки словарей. Он ставит вопрос украинской медицинской терминологии на обсуждение секции, призывает членов секции работать над составлением словаря и сам ведет такую работу: до 1917 года он проработал термины на буквы А-M.

Публикуя на украинском языке первые научно-медицинские труды, члены секции употребляли термины, которые применялись в литературной и разговорной речи, в быту и сохранились до сих пор, например: більмо, блювота, вивих, вилив крові, запалення, запаморочення, зіничя, знесилення, кашель, корчі, кровотеча, ліки, набряк, недуга, нудота, операція, параліч, пацієнт, пульс, синьиі, харкотиння, шпиталь и т.п. Большинство специальных медицинских терминов авторы создавали на основе латинской терминологии, используя их в форме, которая сохраняется до настоящего времени (иногда с незначительными изменениями орфографии): анальгезія, анестезія, аневризма, антагоністи, антитіла, артерія и т.п.

Часто названия болезней писали на латинском или немецком языках. Вместе с тем, в тексте этих первых работ встречается немного названий болезней и терминов, перенесенных непосредственно из народной речи. Из-за недостаточной ясности изложения такие термины чаще представляли параллельно с латинскими или немецкими. Например: боляк, гнойовик (абсцес), б’ючка (артерія), водниця (водянка), гніт (тиск), жили (судини), заникливість (атрофія), збур (запалення), зизооче (зизоокість), злучниця (кон'юнктива), кила або гила (грижа), мізківка (сітківка), новорости (новоутвори), очна банька (очне яблуко), плин (рідина), прозорка (рогівка), полуда (катаракта), сечепуст (сечовипускання), слизниия (слизова оболонка), сочка (кришталик), ураз (матка), ятрити (подразнювати) и др.

Киевский хирург Мартирий Галин был одним из активнейших создателей украинской медицинской терминологии, подобно, как и львовский врач Евгений Озаркевич, стремился развивать украинскую научную медицинскую терминологию на основе украинского языка и народных терминов, и делать это на примере традиций формирования терминология в латинском и греческом языках. Как большую заслугу перед украинской наукой исследователя О.Корчака-Чепурковского отмечают тот факт, что большая часть чисто украинских и заимствованных из латинского языка терминов, впервые внедренных им в номенклатуру болезней, осталась в ней на все последующие десятилетия, стала основой современной украинской медицинской терминосистеме.

C анализом потребности упорядочения научной речи медицинских текстов выступил академик НАМН Украины М.П.Павловский, автор, научный редактор многих научных трудов на украинском языке, составитель словарей (Kononenko 1996). Он отмечал, что частым нарушением норм украинского языка является злоупотребление чужой лексикой, применение неукраинских словообразований, слов-перевертышей, двусмысленность высказываний, копирование российских речевых оборотов. Некоторые термины переносятся в украинский язык без перевода, например: озноб (вместо лихоманка), спайки (зрощення, злуки), бинтування (бандажування). Неправильно используются суффиксы в терминах, 
например: регуляторні (замість регуляційні), овуляторні (овуляційні), компенсаторні (компенсаційні), пальпаторно (пальпаційно), медикаментозне (медикаментне). Неправильное употребление таких слов, как непереносимість (замість несприйнятливість), оперативне втручання (операційне), паренхіматозний (паренхімний), медико-хірургічна (має бути медично-хірургічна), згортання крові (зсідання) и др.

За годы независимости Украины проведена большая работа по разработке украинской научной терминологии, в т.ч. медицинской. Проходят конференции по проблемам украинской терминологии, в т.ч. всеукраинские и международные. В некоторых словарях нашли отражение и новые попытки формирования украинской медицинской терминологии: Мусий А., Нечаев С., Соколик А., Гаврилюк С., «Російсько-український медичний словник», Киев, 1991; Умань, 1992; Нечай, С. «Словник чужослів мови медика», Киев, 2000; Нечай, С. «Російсько-український медичний словник 3 іншомовними назвами» (Київ: «Третє тисячоліття», 2000) насчитывает 15000 слов, указана основная медицинская иноязычная терминология, слово-источник. Авторы предлагают несколько украинских соответствий, на последнем месте то, который считался до сих пор приемлемым или даже единственным.

Широкое признание специалистов-медиков и лингвистов получил изданный под редакцией М.П.Павловского и др. двухтомный "Українсько-латинсько-англійський медичний тлумачний словник” (Львов, 1995), который охватывает 33 тыс. терминов. Ценным изданием для тех, кто впервые начал писать медицинские труды на украинском языке, стал “Російськоукраїнський словник медичної термінології” (Наукова думка, Киев, 1996). В нем переведены 30000 медицинских терминов, которые широко используются современной наукой. К одному русскому термину пподан один украинский эквивалент, но если в украинском языке встречаются синонимы, то они подаются в последовательности от нормативного, эквивалентного и наиболее употребляемого в языке. (Ganitkevich 2002; Petruh 2014 и др.)

Мы пересказали некоторые примеры из исследований украинский специалистов, которые разрабатывают медицинскую терминологию. Эти материалы используются в высшей школе Украины в лекциях по терминоведению. Задача нового курса, предлагаемого нами, состоит в том, чтобы системно усвоить не только терминологический, но и украиноведческий материал, который будет способствовать национальному воспитанию студентов средствами языка, культуры и украиноведения, обеспечит высокое интеллектуальное развитие, будет способствовать повышению профессиональной, языковой, культурологической, медиаобразовательной, социокультурной и коммуникативной компетенций.

По учебному плану предусмотрено лекционный курс, практические занятия, самостоятельная работа и индивидуальные задания. Кроме ярко выраженной познавательной направленности, предлагаемая дисциплина имеет важное воспитательное значение, содержит два блока: «Общее лингвоукраиноведение» и «Медицинское / фармацевтическое лингвоукраиноведение». Отраслевой (второй) блок состоит из нескольких комплексных темзанятий. Представим некоторые из их:

1. Растительные слова-символы. Символы - названия существ. Символика предметных названий. Лечебные растения и их свойства. Народные названия лекарственных растений: украиноведческий аспект. Символика названий явлений природы.

2. Украинские названия болезней, происхождение, признаки, способы лечения. Украинские названия болезней в лингвистических исследованиях. 
3. Украиноведение: народные методы лечения: от древности до современности. Термины украинского происхождения.

На практических занятиях студентам предлагается ознакомиться и представить с позиций лингвоукраиноведения профессиональные издания, сайты, блоги, обратить внимание на украиноязычные названия соответствий. Предлагаются: 1) «Фармацевтична енциклопедія» украинское справочное издание, которое содержит статьи по фармацевтической науке и практике: конструирования лекарственных систем, представляет методы контроля и реализации, сертификации, стандартизации лекарственных средств, изучения лекарственных растений лабораторная диагностика и тому подобное. Энциклопедия предназначена для работников фармацевтической отрасли, врачей, студентов. 2) «Ліка́рські росли́ни: енциклопеди́чний довідник» - украиноязычное справочное издание, рассчитанное на врачей и широкий круг всех, кто интересуется лекарственными растениями. Справочник содержит 1297 статей и 754 иллюстрации. В книге кратко описаны лекарственные растения, рассмотрены их морфологические и ботанические сведения, способы заготовок, хранения и использования, представлены их химический состав. Приведены распространенные рецепты приготовления лекарств с применением целебных растений.

Еще одно практическое занятие посвящено новейшим медиаисточниками, способствует развитию медиакомпетентности будущих специалистов. Обращение, например, к представлению фармацевтической отрасли в Украинской Википедии ориентирует студентов на поиск профессиональных статей, на их наличие в латинском и англоязычном разделах Википедии, что улучшает знания профессиональных понятий на этих языках: Самостоятельная работа по профессионально ориентированной дисциплине «Отраслевое лингвоукраиноведение» включает в себя проработку лекционного материала, подготовку к практическим занятиям, а также обработку материала, который не излагается на лекциях. Поэтому целью самостоятельной работы по курсу является развитие социокультурной, коммуникативной и медиаобразовательной компетенций соискателей высшего медицинского образования, приобретения ими знаний социально-культурной маркованности.

ВЫВОДЫ. Функционирование и совершенствование медицинской терминологии под углом профессионально ориентированного лингвоукраиноведения поможет расширить профессиональную, языковую, культурологическую компетентности будущих специалистов. Считаем целесообразным предложить подобный курс в высшие учебные заведения разных направлений подготовки.

\section{LIST OF REFERENCES}

Vereschagin, E.M., Kostomarov V.G. (1999). V poiskah novyih putey razvitiya lingvostranovedeniya: kontseptsiya reche-povedencheskih taktik. - M.

Vereschagin, E.M., Kostomarov V.G. (1973). Yazyik i kultura. - M.

Vorobev, V.V. (1997). Lingvokulturologiya (teoriya i metodyi): Monografiya. -M.: Izd-vo RUDN.

GanItkevich, Ya. (2002). UkraYinskI lIkarI-vchenI pershoYi polovini HH stolIttya ta YihnI naukovI shkoli: bIogr. narisi ta bIblIogr. / Yaroslav GanItkevich. - LvIv, 540 s. - ZI zmIstu: [M. Panchishin]. - S. 7, 173, 265, 266, 338-370, 373, 430. 
GanItkevich Yaroslav / Yaroslav Hanitkevych. Rozvitok ukraYinskoYi medichnoYi termInologI Opubllkovano 2021-01-24 // https://ntsh.org/node/1018. Data pereglyadu 15.03.21.

Donets, Z.F. (2002). Pro zasobi vihovannya novoYi lyudini - kulturoznavstvo sontra kulturologIYi// Vischa osvIta UkraYini, - \# 4. - S. 104 - 107.

Kononenko, P.P. (1996). UkraYinoznavstvo: pIdruchnik. - K.: LibId.

Kostomarov, V.G., Burvikova N.D. (1999). Edinitsyi semioticheskoy sistemyi russkogo yazyika kak predmet opisaniya i usvoeniya// Materialyi IH Kongressa MAPRYaL: Bratislava, 1999. - M. - S. 252260.

MIsnik, Natallya, Simonenko, Lyudmila (2002). Pro "stan zdorov'ya" movi meditsini (termInologIchniy aspekt) // Problemi ukraYinskoYi termInologIYi. VIsnik Nats. un-tu "LvIv.polIt.". - \# 453, - S. 262269.

Onkovich, A.D. Onkovich, G.V. (2018). KonferentsIya «Mova I kultura» yak Interaktivna medIaosvItnya tehnologIya // MOVA I KULbTURA. (Naukoviy zhurnal), K.: Vidavnichiy dIm Dmitra Burago, - T. 191. - S. $486-491$

Onkovich, G. (1999). LIngvoukraYinoznavstvo na urokah rozvitku movlennya // Divoslovo, \# 3. S.7-14.

Onkovich, G.V. (1997). UkraYinoznavstvo I IIngvodidaktika. - K., - 105 s.

Onkovich, G.V. (2001). «UkraYinoznavstvo I lIngvodidaktika» - serIya navchalnih knig z IIngvoukraYinoznavstva // Problemi pIdruchnika dlya vischoYi shkoli : zb. materIalIv nauk -metod. konf., VInnitsya, 29-30 trav. 2001 - VInnitsya: UnIversum, - T. 2. - S. 51-55.

Onkovich, G.V. (2003). KulturologIchna aura yak pedagogIchna spadschina M.P.Dragomanova: MaterIali pershih MIzhnarodnih dragomanovskih chitan: 30 veresnya-2 zhovtnya 2003 r. / Ukl. G.I.Volinka, V.P.SergIEnko, L.L.Makarenko. - K.: NPU ImenI M.P.Dragomanova, Vipusk 2. - 274 s. - S.109-114.

Onkovich, G.V. (1993). LIngvoukraYinoznavstvo na zanyattyah z rozvitku movlennya// Ukr. mova ta lIt-ra v shkolI. - \# 2. - S. 7-16.

Onkovich, G.V. (1999). UkraYinolIngvoznavstvo ta IIngvoukraYinoznavstvo - chi totozhnI tsI ponyattya? // Nauka I suchasnIst: zb. nauk. pr. / Nats. ped. un-t Im. M. P. Dragomanova ; redkol.: M. I. ShkIl (golova) [ta In.]. - KiYiv: Logos, - Ch. III. - S. 141-149.

Onkovich, G.V. (1994). Slovo-tema yak zgornutiy natsIonalno-kulturniy tekst I metodika yogo aktualIzatsIYi v auditorIYi studentIv-InozemtsIv // Tekst i metodika ego analiza: materialyi VII Mezhdunar. nauch. konf. -Harkov: [b. i.]. - S.98-102.

Onkovich G.V. (2010). Hata: slovo-tema I kulturoznak. MovnI stilI : navch. posIb. / G. V. Onkovich ; NAPN UkraYini, In-t visch. osvIti. - KiYiv : [In-t visch. OsvIti NAPN UkraYini], - $71 \mathrm{s.}$

Onkovich, Ganna (2011). «DIalog kultur» yak suchasna pedagogIchna tehnologIya // Vischa osvIta UkraYini : teoret. ta nauk.-metod. chasop. / In-t visch. osvIti NAPN UkraYini. - KiYiv, - \# 4. - S. 4248.

Pavlovskiy, M.P. (2005). Sche raz pro potrebu uporyadkuvannya naukovoYi movi medichnih tekstIv. Shpitalna hIrurgIya. - \# 2. - S. 6-15 
Petrova, Olga. (1998). Dzherelna baza IIngvIstichnogo doslIdzhennya narodnoYi medichnoYi termInologIYi v ukraYinskIy movI. Problemi ukr. termInologIYi. VIsnik derzhavnogo unIversitetu «LvIvska polItehnIka» \# 336.LvIv, - 289-291)

Petruh, L. (2014). Istorlya rozvitku medichnogo slovnikarstva / L. Petruh // PratsI naukovogo tovaristva Im. Shevchenka. LIkarskiy zbIrnik. Meditsina I bIologIya. - 2014. - T. 38, T. 24. - S. 22-33. - Rezhim dostupu: http://nbuv.gov.ua/UJRN/pntsh_lik_2014_38_24_6.

Shevchuk, S.V., Klimenko I.V. (2011). UkraYinska mova za profesIynim spryamuvannyam : PIdruchnik. 2-ge vid., viprav I dopovnen -K Alerta, - 696 s.

\section{For citation:}

Onkovych, A. (2021) Sectoral linguo-country studies (on the example of medical linguo-Ukrainian studies) // International Scientific-Pedagogical Organization of Philologists "WEST-EAST" (ISPOP). Scientific Journal “WEST-EAST". Vol. 5, N1 (March, 2021). pp. 91-101. https://doi.org/10.33739/2587-5434-2021-3$\underline{1-91-101}$

\section{Для цитирования:}

Онкович, А. В. (2021) Отраслевое лингвострановедение (на примере медицинского лингвоукраиноведения) // International Scientific-Pedagogical Organization of Philologists "WESTEAST" (ISPOP). Scientific Journal "WEST-EAST". Vol. 5, N1 (March, 2021). c. 91-101. https://doi.org/10.33739/2587-5434-2021-3-1-91-101

\section{Information about the author:}

Anna Onkovych - Doctor of Pedagogical Sciences, Professor of the Department of Ukrainian and Latin Languages, Kyiv Medical University, full member of the T. Shevchenko Scientific Society, member of the editorial boards of scientific professional publications ("Обрії друкарства" - Editor-in-chief, "Вища освіта України" - from the day the publication was founded to 2015, deputy editor-in-chief, "Мова і культура",“ Дивослово”,“ Наукові студії", "Креативна педагогіка", "WEST-EAST"). For many years, she headed the bureau of the journal "Рідна школа" (USA) in Ukraine. Moderator of 15 pages of professionally-oriented pages on the social network Facebook. Kyiv, Ukraine.

email: onkan@ukr.net

\section{Сведения об авторе:}

Онкович Анна Владимировна - доктор педагогических наук, профессор кафедры украинского и латинского языков, Киевский медицинский университет, член Научного общества имени Т. Г. Шевченко, член редакционных коллегий научных профессиональных изданий ("Обрії друкарства" главный редактор, "Вища освіта України" - со дня основания издания до 2015 года, заместитель главного редактора, "Мова і культура","Дивослово", "Наукові студії", "Креативна педагогіка", "WEST-EAST"). В течение многих лет возглавляла бюро журнала "Рідна школа". (США) в Украине. Модератор 15 страниц профессионально ориентированных страниц в социальной сети Facebook.

Киев, Украина

email: onkan@ukr.net 